\title{
Optimization of Atomized Spray Cutting Fluid Eco- Friendly Turning of Inconel 718 Alloy Using ARAS and CODAS Methods
}

\section{Vinothkumar Sivalingam ( $\sim$ svkceg@gmail.com )}

Shandong University https://orcid.org/0000-0002-6705-5933

\section{Ganeshkumar Poogavanam}

Yeungnam University

\section{Yuvaraj Natarajan}

Vel Tech Rangarajan Dr. Sagunthala R \& D Institute of Science and Technology

Jie Sun

Shandong University

\section{Research Article}

Keywords: Inconel 718 alloy, Turning, Desirability functional analysis, Multi-criteria decision making (MCDM), surface roughness, tool life, machining cost, ARAS method, CODAS method

Posted Date: October 22nd, 2021

DOI: https://doi.org/10.21203/rs.3.rs-988214/v1

License: (c) (i) This work is licensed under a Creative Commons Attribution 4.0 International License. Read Full License

Version of Record: A version of this preprint was published at The International Journal of Advanced Manufacturing Technology on March 17th, 2022. See the published version at https://doi.org/10.1007/s00170-022-09047-w. 


\title{
Optimization of Atomized Spray Cutting Fluid eco-friendly turning of Inconel 718 alloy using ARAS and CODAS methods
}

Vinothkumar Sivalingam ${ }^{1,2} \mathrm{a}^{*}$, Ganeshkumar Poogavanam ${ }^{3,}$ a , Yuvaraj Natarajan ${ }^{4}$ Jie $_{\text {Sun }}^{1,2^{* *}}$

${ }^{1}$ Key Laboratory of High-efficiency and Clean Mechanical Manufacture, National Demonstration Center for Experimental Mechanical Engineering Education, School of Mechanical Engineering, Shandong Uni-versity, Jinan 250061, Shandong, China.

${ }^{2}$ Research Center for Aeronautical Component Manufacturing Technology \& Equipment, Shandong University, Jinan 250061, Shandong, China

${ }^{3}$ School of Mechanical Engineering, Yeungnam University, Gyeongbuk 712-749, Republic of Korea.

${ }^{4}$ Vel Tech Rangarajan Dr. Sagunthala R \& D Institute of Science and Technology, Avadi, Chennai-62, India.

*Correspondence: svkceg@gmail.com (VK.S); sunjie@sdu.edu.cn(J.S)

${ }^{a}$ Authors contributed equally to this work.

\begin{abstract}
Atomized spray cutting fluid (ASCF) is a sophisticated machining technique that achieves higher productivity, enhanced surface quality, extended tool life, and cost benefits. This research aims to analyze the influence of cutting process parameters on Inconel 718 alloy turning in dry and ASCF cutting environments. The critical machining indices such as surface roughness, machining cost, power consumption, and tool life were analyzed concerning these two cooling environments. The cutting parameters were optimized using desirability functional analysis and two types of multicriteria decision making (MCDM) method, such as additive ratio assessment method (ARAS) and combinative distance-based assessment (CODAS) method, were investigated. The composite desirability index (CD) of optimum parameter setting $\left(\mathrm{A}_{2} \mathrm{~B}_{1} \mathrm{C}_{2} \mathrm{D}_{2}\right)$ is improved by $6.34 \%$ compared to the initial parameter setting $\left(\mathrm{A}_{2} \mathrm{~B}_{1} \mathrm{C}_{2} \mathrm{D}_{1}\right)$. The optimum parameters from the MCDM technique are obtained as a cutting speed of $200 \mathrm{~m} / \mathrm{min}$, feed rate of $0.08 \mathrm{~mm} / \mathrm{rev}$, and depth of cut of $0.2 \mathrm{~mm}$ under ASCF environment. ASCF machining significantly minimize the surface roughness, machining cost and power consumption, maximize the tool life by about 16\%, 51\%, $17 \%$ and $48 \%$ respectively as compared with dry machining
\end{abstract}

Keywords: Inconel 718 alloy; Turning; Desirability functional analysis, Multi-criteria decision making (MCDM); surface roughness; tool life; machining cost; ARAS method; CODAS method. 


\section{Introduction}

Titanium and nickel-based superalloys are the essential metallic materials used in aircraft construction and mechanical components. Because this superalloy has high heat resistant properties, it is therefore used extensively. Inconel 718 alloys are categories under complex materials challenge to the machining industries. Therefore, this high temperature/heat resistant material requires low-cost and high-performance machining solutions and methods[1]. Li et al. [2] conducted a study on tool wear using two distinct inserts: a coated carbide insert and a ceramic insert. The study revealed that the wear mechanism of these two cutting tools was similar to that of abrasion, chipping, and adhesion. For machining Inconel 718 alloy, ceramic insert with a negative angle is more suitable. The impact of various parameters on the performance of hard AISI-D2 steel using ceramic insert was analyzed by Gaitonde et al [3]. They concluded that the depth of cut greatly influences the tool wear and the production of uniform surface roughness of the materials. Tool wear was studied during the turning of In800 with a cubic boron nitride $(\mathrm{cBN})$ insert while choosing the best cutting conditions. To increase tool life and improve surface finish, the investigators also recommend coated carbide tools, and vegetable oil assisted MQL solid additives. [4].

Singh et al. [5] have made the comparison of properties of cold air-assisted and biodegradable oil-based MQL during the machining of pure titanium. The authors concluded that the cold air assisted MQL provided better surface quality and lowered the tool wear while improving the cutting forces. Researchers have taken many steps are taken to increase production efficiency at a very low cost. Many researchers followed specific methods (Dry, MQL, Cryogenic machining) to increase production efficiency at a very low cost. Still, most of the machining industries have used cutting fluids to enhance machining efficiency. Minimum quantity lubrication (MQL) is the term that is about $1 / 3 \mathrm{rd}(50-100 \mathrm{~mL} / \mathrm{hr})$ of cutting fluid is used when compared to flood cooling. Benefits of MQL in machining extend tool life, and quality machined surface[6]. Few researchers have studied the effects of atomized spray cutting fluid (ASCF) on titanium and nickel base alloy materials. The main issue with Inconel 718 machining is creating a high cutting temperature in a work-tool interface that can react with the tool's coating [7]. The increasing cutting speed $\left(v_{\mathrm{c}}-100 \mathrm{~m} / \mathrm{min}\right)$ can result in higher 
cutting forces and temperature in the machine tool zone, affecting its surface integrity and productivity[8].

The concept of ASCF was developed to improve the tool life while reducing the coolant consumption in Inconel 718 alloy machining. Cutting fluid mixed with water at different ratio (96:4-90:10) is commonly used as the cutting fluid in the ASCF/MQL process. The mixtures are used to minimize environmental impacts. This process involves using atomized fine droplets of cutting liquid $(5-10 \mu \mathrm{m})$ that enter a machine zone and reduce the temperature and wear of the tool[9]. Sivalingam et al. [10] implementing the ASCF method involves using a solid additive lubricant such as graphite and molybdenum di- sulphide $\left(\mathrm{MoS}_{2}\right)$. The objective of this procedure is to minimize the harmful effects of environmental pollution. This method delivers fine droplets of a cutting fluid over the tool-chip interface region, which offers better heat dissipation and reduced friction. Sartoriet et al. [11] performed experiments on Ti-6Al-4 $\mathrm{V}$ with a minimum quantity of liquid lubricant (MQL). Solid lubricant (SL) -assisted minimum quantity cooling (MQC) technique with different aqueous solutions with varying percentages of graphite. The results indicated that the SL- MQC technique provided the best performance for the tool wear and surface integrity. The machine tool industry's function is to improve productivity and efficiency, which is closely connected with identifying the appropriate cutting parameters. [12]. Unfortunately, finding the optimal combination between feed rate, depth of cut, and cutting speed can be challenging. Doing so can improve the surface finish, reduce the tool wear rate, and improve overall productivity[12,13]. The Desirability function is a procedure that can be used to convert the complex multi-response characteristics to single response. Sait et al[14] . conduct the turning experiment on the glass -fiber- reinforced plastic (GFRP) and optimize the process parameter by using desirability function analysis (DSA). Similarly, the optimized cutting parameters were selected for turning of EN25 steel with different coated carbide tools. The results were presented at cutting speed of $244 \mathrm{~m} / \mathrm{min}$, feed rate of $0.10 \mathrm{~mm} / \mathrm{rev}$ and depth of cut of $1.0 \mathrm{~mm}$ with CVD coated tool is optimum parameter in the form of desirability functional analysis[15]. Swiercz et al.[16] attempted to study the influence of machining parameters on material removal rate (MRR), surface roughness (Sa) and white layer thickness (WL) during electrical discharge machining (EDM) by response surface methodology (RSM) and desirability function (DF). The discharge current and discharge time had the most influence on the MRR, Sa, and WL. Vijay Kumar Sharma et al. [17] investigated the machinability of EN 31 steel under dry, MQL and flood cooling using Taguchi based DF. The highest composite desirability (CD) value of 0.9879 was noticed under 
flood cooling at the cutting speed of $110 \mathrm{~m} / \mathrm{min}$, feed rate of $60 \mathrm{~mm} / \mathrm{min}$ and depth of cut of $0.4 \mathrm{~mm}$.

Several researchers have implemented the multi-criteria decision making (MCDM) tool for various sectors such as manufacturing, thermal, supplier selection, finance, and solar application[18]. Singaravel et al.[19] applied the additive ratio assessment (ARAS) technique to determine the optimal process factors (cutting speed, feed rate, and depth of cut) and appropriate coated tools to turn the operation with AISI 4340 steel. They suggested the optimum combination of cutting parameters for rapid reduction of surface roughness, microhardness, and maximize of material removal rate (MRR) are $161 \mathrm{~m} / \mathrm{min}$ cutting speed, $0.24 \mathrm{~mm} / \mathrm{rev}$ feed rate, and $1.2 \mathrm{~mm}$ depth of cut through CVD coated tool. Ghenai et al.[20] optimized the sustainability indicators for renewable energy (RE) systems, namely solar photovoltaic, wind energy, phosphoric acid fuel cell, and solid oxide fuel cell using the ARAS and step-wise weight assessment ratio technique. In this study, five different sustainability criteria were identified for different industries namely resource, environment, social, economic, and technology. The criteria were then used to evaluate the various sub-categories of energy construction. According to their findings, land-based wind energy systems are rated highest in terms of sustainability pointers and sub-points, followed by solid oxide and then phosphoric acid fuel cells, with polycrystalline solar energy systems rated last. Marichamy et al. [21] found the optimal process parameters and appropriate for the welding operation of A319 Aluminum alloy using the ARAS method. The optimum arrangement of joining consideration welding feed is $40 \mathrm{~mm} / \mathrm{min}$, the rotation speed is $700 \mathrm{rpm}$, and tool pin diameter is $6 \mathrm{~mm}$ for joining the component. Kumar et al.[22] optimized the AA7050-10(wt.) \% B4C composite using fluxassisted stir casting technique and its machinability with die-sinking EDM using ARAS, grey relational analysis, and Taguchi method. They found the ARAS technique provides the minimum percentage error compared with the grey relational analysis. Henceforth, the ARAS technique is a suitable tool for optimizing the process parameters of EDM.

Ramezanali et al.[23] suggested a decision-making methodology based on the Best-Worst and ARAS techniques to assign weightage to the spatial proxies for ore-forming minerals processing. In the investigation area, the results of this technique were compared with TOPSIS and those of index-overlay, exposing the advantage of the ARAS technique. Goswami et al. [24] selected the best alternative material for engineering applications amongst the seven alternatives based on the six sub-criteria (bending fatigue limit, core hardness, cost, surface hardness, ultimate tensile strength, and surface fatigue limit) through the ARAS approach. It is 
concluded from their results that cast alloy steel is the good choice succeeded by cast iron and carburized steels, considering hardened alloy steel is the bad selection amongst the group. Balki et al.[25] analyzed the engine operating factors through SWARA and ARAS hybrid technique with a small SI engine using alternative fuels. Based on the outcomes, the optimal working factors were attained to be 9.0:1 of compression ratio, 1.1 of air excess coefficient, and crankshaft angle of $20^{\circ}$ of ignition timing in the usage of pure methanol fuel. Çolak et al.[26] suggested the energy storage alternatives are entirely critical and can be accurately measured as an MCDM problem. They evaluated this difficulty relating to both quantitative and qualitative criteria. They found that the energy storage technologies (EST) alternative termed "Compressed Air" has been recommended as the best appropriate energy storage technology choice for Turkey. Radović et al.[27] studied the performance measurement in transportation companies according to 20 performance indicators using the ARAS approach. Their outcomes display that transportation enterprises from Serbia and Bosnia and Herzegovina are suggestively aforementioned transportation enterprises from Libya. Keshavarz Ghorabaee et al.[28] a fuzzy extension of the CODAS technique used for finding the market segment evaluation and selection. It is observed from the results displays that the fuzzy CODAS technique is effective and reliable compared with the other approaches, and the sensitivity analysis proves the constancy of the outcomes of the suggested technique. A new CODAS technique was used for selecting the wind energy plant locations suggested by Karaşan et al. [29]. The sensitivity analysis revealed that the specific output for the wind plant location is moderately robust. Researchers have applied CODAS techniques in different applications, such as supplier selection [30], energy storage[31], machine tool selection [32], material selection [33,34], location selection[35] and market segment [28] have been broadly examined.

This paper aims to identify, evaluate and optimum turning process parameters for achieving a high-quality response for Inconel 718 alloy based on a desirability approach, ARAS and CODAS MCDM approach. The $\mathrm{L}_{18}$ Taguchi orthogonal array (OA) experiment is carried out to evaluate the optimal process parameters for surface roughness, machining cost, power consumption and tool life. The current paper provides an integrated MCDM technique for determining the best turning parameters based on the above research. Consequently, our study makes a valuable contribution in filling the aforementioned gap. 


\section{Materials and Methods}

Inconel 718 alloy (DAEWOO PUMA-2000, China) was machined using CNC turning machining. Ceramic insert with SNGA $120412 \mathrm{~T}$ T01-WG 300 grade $\left(\mathrm{Al}_{2} \mathrm{O}_{3}+\mathrm{SiC}\right.$ whiskers $)$ and MSDNN 2525 M12-Greenleaf Corporation, USA is used as a tool holder for machining. Figure 1 shows the schematic diagram for the dry and ASCF methods. The present study employs the ASCF method to examine the effect of cutting fluid with solid lubricants on tool wear. Dry machining is also used to prove that the ASCF process is better. In the ASCF method, two types of solid lubricants such as graphite and molybdenum disulfide $\left(\mathrm{MoS}_{2}\right)$ were used. To guarantee homogeneous particle dispersion, 0.2 weight percent of each solid lubricant is combined in $20 \mathrm{ml}$ with acetone. Next, cutting fluid mixed with solid lubricant with ratio of 90:10. With an air pressure of 7 bar, the flow adjusted valve engages the coolant flow rate of $30 \mathrm{~mL} / \mathrm{h}$. The nozzle-to-tooltip distance is fixed at $50 \mathrm{~mm}$. For each experiment, a new cutting insert is used to accurately examine machining performance. The surface roughness of the workpiece was measured with a contact-type surface roughness tester (TR200) (Ra). The complete details of the experimental work are illustrated in Table 1.

\section{Optimisation}

3.1.Desirability function analysis

The concept of the desirability function was proposed by Harrington[36]. The desirability approach combines the functions $[0,1]$ to create a standard scale metric. It works by transforming each estimated response $\mathrm{y}_{\mathrm{i}}$, into a unitless utility bounded $\mathrm{By} 0<\mathrm{d}_{\mathrm{i}}<1[37]$.

(i) Larger the better

The value of $y_{i}$ is expected to be smaller than the desirable value $\left(d_{i}=1\right) \cdot y_{i}>y_{\min }\left(d_{i}=\right.$ 0 ) undesirable value. $d_{i}$ values lie in the range of [0 1] is defined by Equation (1).

$$
d_{i}=\left\{\begin{array}{c}
{ }^{0}\left(\frac{y_{i}-y_{\min }}{y_{\max }-y_{\min }}\right)^{s}, y_{\min } \\
y_{\text {min }} \leq y_{i} \leq y_{\max }, s \geq 0 \\
y_{i}>y_{\max }
\end{array}\right.
$$

(ii) Smaller the better 
The value of yi is expected to be larger than the desirable value $(\mathrm{di}=1)$. yi $<$ ymin $(\mathrm{di}$ $=0$ ) undesirable value. di values lie in the range of [0 1] is shown in Equation (2).

$$
d_{i}=\left\{\begin{array}{c}
y_{i}<y_{\min } \\
\left(\frac{y_{i}-y_{\max }}{y_{\min }-y_{\max }}\right)^{r}, y_{\min } \leq y_{i} \leq y_{\max }, r \geq 0 \\
y_{i}>y_{\max }
\end{array}\right.
$$

Composite desirability (CD) is presented in Equation (3). $\mathrm{d}_{1}, \mathrm{~d}_{2}, \mathrm{~d}_{3}$ are the individual desirable index. $\mathrm{w}_{1}, \mathrm{w}_{2}, \mathrm{w}_{3} \ldots$. weightage value.

$$
C D=\left(d_{1}^{w 1} x d_{2}^{w 2} x d_{3}^{w 3} x \ldots\right)^{1 / k}
$$

\subsection{Entropy method}

The Shannon entropy is a method that calculates the weights of decision criteria after taking the initial decision matrix[38].

Step 1: Project outcome (Pij) is obtained by normalising the arrays of a decision matrix.

$$
P_{i j}=\frac{x_{i j}}{\sum_{i=1}^{m} x_{i j}}
$$

Step 2: Calculation of the entropy measure of project outcomes

$$
E_{j}=-k \sum_{i=1}^{m} P_{i j} \times \ln P_{i j}, \quad\left(k=\frac{1}{\ln (m)}\right)
$$

Step 3: Defining the objective weight based on the entropy concept

$$
W_{j}=\frac{1-E_{j}}{\sum_{j=1}^{n}\left(1-E_{j}\right)}
$$

\subsection{Additive ratio assessment method (ARAS)}

The ARAS is a conceptual evaluation system developed by Zavadskas and Turskis in 2010[39]. ARAS is a conceptual model that compares the performance of various alternatives to the ideal alternative[40]. This method is used in various fields of study. 
Step 1: Forming of Decision - making matrix (DMM)

$X=\left[\begin{array}{cccc}x_{01} & x_{02} & \ldots . . & x_{0 n} \\ x_{11} & x_{12} & \ldots . . & x_{1 n} \\ \cdot & \cdot & . & \cdot \\ \cdot & \cdot & . & \cdot \\ x_{m 1} & x_{n 2} & \ldots . . & x_{m n}\end{array}\right], \quad(i=0,1, \ldots, m ; j=1,2, \ldots, n)$

$x_{o j}=\left\{\begin{array}{c}\operatorname{Max} x_{i j} \text { if } j \in \text { Beneficial } \\ \text { Min } x_{i j} \text { if } j \in \text { NonBeneficial }\end{array}\right\}$

Step 2: Normalization of Decision Matrix

$$
\overline{x_{i j}}=\frac{x_{i j}}{\sum_{i=0}^{m} x_{i j}} \quad\left[x_{i j}=\frac{1}{x_{i j}^{*}} ; \quad \overline{x_{i j}}=\frac{x_{i j}}{\sum_{i=0}^{m} x_{i j}}\right]
$$

Step 3: Weighted Normalized Decision Matrix

$$
\begin{aligned}
& \boldsymbol{t}_{i j}=\boldsymbol{t}_{i j} w_{j} ; i=0, \ldots . m, \quad \sum_{j=1}^{n} w_{j}=1
\end{aligned}
$$

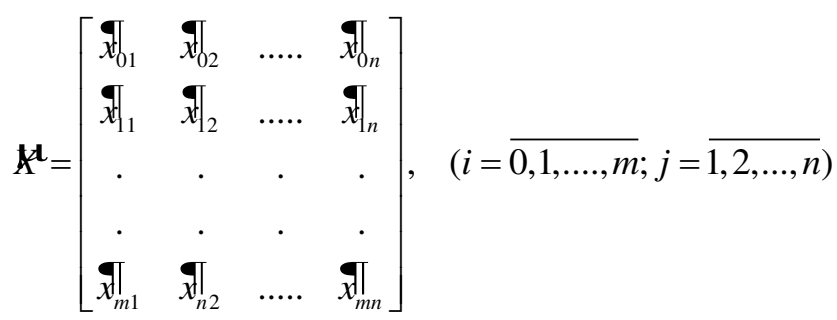

Step 4: Determine the optimality function Si for the alternative

$$
S_{i}=\sum_{j=1}^{n} \boldsymbol{\mu}_{i j}, \quad\left(\begin{array}{c}
i=0, . ., m \\
j=1, \ldots, n
\end{array}\right)
$$

Step 5: Determine the Degree of utility Ki for Each of the alternatives

$$
K_{i}=\frac{S_{i}}{S_{o}} ; i=0, \ldots, m
$$


A new type of decision-making method known as CODAS is proposed to consider problems with multi-criteria decisions. The method is formulated by taking into account the Euclidean distance of alternatives from the negative-.[28].

Step 1: Developing the initial decision matrix

$$
X=\left[x_{i j}\right]_{n \times m}=\left[\begin{array}{cccc}
x_{11} & x_{12} & \ldots . . & x_{1 m} \\
x_{21} & x_{22} & \ldots . . & x_{2 m} \\
\cdot & \cdot & . & \cdot \\
\cdot & . & . & \cdot \\
x_{n 1} & x_{n 2} & \ldots . . & x_{n m}
\end{array}\right]
$$

Step 2: Normalize decision matrix

$$
n_{i j}=\left(\begin{array}{ll}
\frac{x_{i j}}{\max x_{i j}} & \text { if } j \in \text { Beneficial } \\
i & \\
\frac{\min x_{i j}}{x_{i j}} & \text { if } j \in \text { NonBeneficial }
\end{array}\right)
$$

Step 3: Weighted normalize decision matrix

$$
r_{i j}=w_{j} n_{i j}
$$

Step 4: Determine the negative- ideal solution points

$$
n s=\left[n s_{j}\right]_{1 x m}, \quad\left(n s_{j}=\min _{i} r_{i j}\right)
$$

Step 5: Calculate the Euclidean and Taxicab distances of alternatives from the negative- ideal solution

$$
E_{i}=\sqrt{\sum_{j=1}^{m}\left(r_{i j}-n s_{j}\right)^{2}}, \quad T_{i}=\sum_{j=1}^{m}\left|r_{i j}-n s_{j}\right|
$$

Step 6: Construct the relative assessment matrix

$$
\begin{aligned}
& R a=\left[h_{i k}\right]_{m \times n}, h_{i k}=\left(E_{i}-E_{k}\right)+\left(\psi\left(E_{i}-E_{k}\right) X\left(T_{i}-T_{k}\right)\right) \\
& (\text { Assume } \psi=0.02)
\end{aligned}
$$

Step 7: Calculate the assessment score and rank alternatives

$$
H_{i}=\sum_{k=1}^{n} h_{i k}
$$




\section{Results and discussion}

\subsection{Estimated desirability values}

This study aims to determine "smaller the better" and "larger the better" characteristics of individual desirability values to minimize surface roughness, machining cost and power consumption and maximise the tool life. Individual desirability of $\mathrm{d}_{\mathrm{SR}}, \mathrm{d}_{\mathrm{MC}}$ and $\mathrm{d}_{\mathrm{PC}}$ are calculated by Equation (1). Larger the better desirability of $\mathrm{d}_{\mathrm{TL}}$ is calculated by the Equation (2). The $C D_{i}$ values are computed using Equation 3. The equal weightage of 0.25 is considered for all parameters as shown in the table 3. The highest $\mathrm{CD}_{\mathrm{i}}$ values obtained 0.932 and the corresponding $\mathrm{d}_{\mathrm{SR}}, \mathrm{d}_{\mathrm{MC}}, \mathrm{d}_{\mathrm{PC}}$ and $\mathrm{d}_{\mathrm{TL}}$ are $1,0.874,0.912$ and 0.947 respectively.

$$
\begin{aligned}
& d_{S R}=\left\{\begin{array}{c}
y_{i}<0.409 \\
\left(\frac{y_{i}-0.772}{0.409-0.772}\right)^{r}, 0.409 \leq y_{i} \leq 0.772, r \geq 0 \\
y_{i}>0.772
\end{array}\right. \\
& d_{M C}=\left\{\begin{array}{c}
y_{i}<0.308 \\
0\left(\frac{y_{i}-4.3}{0.308-4.3}\right)^{r}, 0.308 \leq y_{i} \leq 4.3, r \geq 0 \\
y_{i}>4.3
\end{array}\right. \\
& d_{P C}=\left\{\begin{array}{c}
{ }^{1}\left(\frac{y_{i}-2.25}{0.306-2.25}\right)^{r}, 0.306 \leq y_{i} \leq 2.25, r \geq 0 \\
y_{i}>2.25
\end{array}\right. \\
& d_{T L}=\left\{\begin{array}{c}
y_{i}<4.6 \\
{ }_{1}^{0}\left(\frac{y_{i}-4.6}{20.2-4.6}\right)^{s}, 4.6 \leq y_{i} \leq 20.2, s \geq 0 \\
y_{i}>20.2
\end{array}\right. \\
& C D_{i}=\left(\begin{array}{ll}
0.810 \times 0.000 \times 0.950 \times 0.423
\end{array}\right)^{\left(\frac{1}{4}\right)}
\end{aligned}
$$

The mean composite desirability factor $\mathrm{CD}$ is shown in figure 3. The response factor at each level on $\mathrm{CD}$ is presented in table 4. The highest $\mathrm{CD}$ is achieved at levels 2,1,2, and 2 for environmental factors, cutting speed, feed rate and depth of cut, respectively. The optimum parameters for the $\mathrm{SR}, \mathrm{MC}, \mathrm{PC}$ and $\mathrm{TL}$ is $\mathrm{A}_{2} \mathrm{~B}_{1} \mathrm{C}_{2} \mathrm{D}_{2}$, i.e Environment (ASCF), cutting speed of $100 \mathrm{~m} / \mathrm{min}$,feed rate of $0.8 \mathrm{~mm} / \mathrm{rev}$ and depth of cut of $0.4 \mathrm{~mm}$ 
The conformation experiment was conducted with optimal parameters. The initial parameter setting at $11^{\text {th }}$ experiment as ASCF environment, cutting speed of $100 \mathrm{~m} / \mathrm{min}$, feed rate of $0.08 \mathrm{~mm} / \mathrm{rev}$ and depth of cut $0.2 \mathrm{~mm}$ is $\mathrm{A}_{2} \mathrm{~B}_{1} \mathrm{C}_{2} \mathrm{D}_{1}$, and the corresponding $\mathrm{CD}$ value is 0.931, as shown in Table 4. An improved $C D$ at the optimum parameter setting $\mathrm{A}_{2} \mathrm{~B}_{1} \mathrm{C}_{2} \mathrm{D}_{2}$ is achieved by optimizing the SR, MC, PC and TL configurations through desirability functional analysis. SR decreased from 0.409 to $0.378 \mu \mathrm{m}$, MC reduced from 0.809 to 0.765 (\$), PC decreased from 0.478 to $0.452 \mathrm{~kW}$ and TL improved from 19.37 to $20.1 \mathrm{~min}$. The percentage improvement observed in SR, MC, PC, TL and CD is noted as 8.2, 5.75, 5.75, 6.43 and 6.34, respectively, as shown in Table 5.

Further, desirability function analysis is compared with well know MCDM techniques such as ARAS and CODAS method. In order to compare the optimal setting parameter with DFA and MCDM techniques. The turning process parameters like SR, TL, MC and PC are optimized with ARAS using the experimental values. First, the individual weightage of each response is calculated by the entropy method from Equation 4-6. Entropy weights for SR, TL, MC and PC are 0.037,0.193,0.496 and 0.274 respectively. The normalized decision matrix and weightage normalized decision are obtained from Equations 7-10. ARAS defines the optimal performance measure as the relative closeness of the optimality function to the measure's highest rank. The function's closeness as the most appropriate value for the evaluation is presented in Equations 11-12. Experiment number 17 has the highest degree of utility value (0.777), as can be observed from the results as shown in table 6 .

CODAS method is used to determine the desirability of alternatives. The two measures are related to the Euclidean distance of alternatives from the negative-ideal. The CODAS measures the performance of an alternative by looking at the distances between the taxicab and the Euclidean distance. If the distance is very close to each other, the CODAS uses the Taxicab distance as the primary measure of comparison. The normalized and weightage normalized performance values are computed for each of the criteria using Equation 13-15. Then, equation 16 calculates the negative-ideal solution. From the negative ideal solution, two alternatives, taxicab and the Euclidean distance also computed, is presented in equation 17. The relative assessment matrix and the assessment scores of alternatives can be calculated using Equation 18-19, as shown in Table 7. Table 7 shows that experiment no. 17 has the highest relative assessment matrix $(\mathrm{H})$ value of 6.971. As a result, in CODAS method evaluation, Experiment number 17 is the optimum process parameter. 
In both MCDM techniques experiment number $17^{\text {th }}$ is the optimal parameter setting for as ASCF environment, cutting speed of $200 \mathrm{~m} / \mathrm{min}$, feed rate of $0.08 \mathrm{~mm} / \mathrm{rev}$ and depth of cut 0.2 $\mathrm{mm}$ is $\left(\mathrm{A}_{2} \mathrm{~B}_{2} \mathrm{C}_{2} \mathrm{D}_{1}\right)$ and the corresponding SR, TL, MC and PC are $0.476,14,0.496$ and 0.274 respectively. There is a variation in the optimal parameter setting in DFA over MCDM techniques this is due to complexity in the mathematical formulation such as entropy weightage, degree of utility and relative assessment matrix. The cutting speed of $200 \mathrm{~m} / \mathrm{min}$ and depth of cut $0.2 \mathrm{~mm}$ is the two factors significantly changed in MCDM techniques other responses feed rate $0.08 \mathrm{~mm} / \mathrm{rev}$ and ASCF machining environment are similar. The same parameter setting $\left(\mathrm{A}_{1} \mathrm{~B}_{2} \mathrm{C}_{2} \mathrm{D}_{1}\right)$ is conducted in dry environment, and the corresponding SR, TL, $\mathrm{MC}$ and $\mathrm{PC}$ are $0.572,7.2,0.631$ and 0.923 respectively.

Figure 4 displays the degree of utility and relative assessment values of Inconel 718 alloy using an ARS and CODAS technique, respectively. It can be noticed from the figure that the 17th experiment is the best experimental condition for both optimization methods, such as ARS and CODAS, due to its higher cutting speed of $200 \mathrm{~m} / \mathrm{min}$, feed rate of $0.08 \mathrm{~mm} / \mathrm{rev}$, and low depth of cut of $0.2 \mathrm{~mm}$ under ASCF environment condition compared with the other experimental conditions. The ARS and CODAS have the highest degree of utility and relative assessment values of 0.7701 and 6.9706, respectively. It can be noticed from Tables 6 and 7 that the worst experimental condition for ADAS was the 9th experimental condition and CODAS was the 7th experimental condition. The ARS and CODAS have the lowest degree of utility and relative assessment values of 0.1974 and -2.6643 , respectively.

The surface defects of dry and ASCF machining at optimum parameters cutting speed of $200 \mathrm{~m} / \mathrm{min}$, feed rate of $0.08 \mathrm{~mm} / \mathrm{rev}$, depth of cut of $0.2 \mathrm{~mm}$ as shown in figure 5 . The scratches and feed marks produced by dry machining are higher than those produced by the atomized spray cutting fluid. This is due to a fine droplet of solid additive lubricant, and vegetable oil improves heat absorption. In addition, fine spray droplets reduce the friction between the tool's tip and the workpiece's surface. This ensures that the sharpness of the tooltip stays at an elevated temperature[41,42]. The generation of an adhesive film at the cutting speed of 200 $\mathrm{m} / \mathrm{min}$ on the rake surface during the turning of an Inconel alloy has been observed. This phenomenon is caused by the high stresses and strain hardening that the alloy undergoes during the machining. Also, the use of spray coolants helps in preventing the formation of abrasion and another diffusion during dry machining. Solid lubricant helps to minimize the amount of heat absorbed by the tool and significantly improve the tool life, as shown in figure 6[43-46]. 


\section{Conclusions}

This paper presents an insightful study on the dry and atomized spray cutting fluid (ASCF) lubrication methods utilized to turn Inconel 718 alloy by applying composite desirability function analysis, ARS, and CODAS methods.

1. The composite desirability index $(C D)$ of optimum parameter setting $\left(A_{2} B_{1} C_{2} D_{2}\right)$ is improved by $6.34 \%$ compared to the initial parameter setting $\left(\mathrm{A}_{2} \mathrm{~B}_{1} \mathrm{C}_{2} \mathrm{D}_{1}\right)$. $\mathrm{CD}$ value of optimum parameter settings 0.994 to $\mathrm{A}_{2} \mathrm{~B}_{1} \mathrm{C}_{2} \mathrm{D}_{2}$ (Environment (ASCF), Cutting speed of $100 \mathrm{~m} / \mathrm{min}$, feed rate of $0.8 \mathrm{~mm} / \mathrm{rev}$ and depth of cut of $0.4 \mathrm{~mm}$ ).

2. ARAS and CODAS MCDM models found that experiment number 17 is ranked first, followed by experiment number 7 and 9 is ranked last. The MCDM identified the optimal machining parameters for minimizing surface roughness, machining cost and power consumption and maximum tool life.

3. The cutting speed of $200 \mathrm{~m} / \mathrm{min}$, feed rate of $0.08 \mathrm{~mm} / \mathrm{rev}$, depth of cut of $0.2 \mathrm{~mm}$ and ASCF environment were the optimum process parameter in MCDM techniques, and the machining output responses surface roughness of $0.476 \mu \mathrm{m}$, machining cost $0.308 \$$, power consumption $0.762 \mathrm{~kW}$ and tool life $14 \mathrm{~min}$.

4. ASCF machining significantly minimize the surface roughness, machining cost and power consumption, maximize the tool life by about $16 \%, 51 \%, 17 \%$ and $48 \%$ respectively as compared with dry machining at the cutting speed of $200 \mathrm{~m} / \mathrm{min}$, feed rate of $0.08 \mathrm{~mm} / \mathrm{rev}$, depth of cut of $0.2 \mathrm{~mm}$.

5. The fine droplet of ASCF helped to improve the wear resistance of the tool (abrasion and diffusion. It also reduced the temperature difference between the tool and the chip, enhance the tool life as compared to dry machining.

Further studies on the effects of various machining parameters on quality responses could be conducted. For instance, different weight $\%$ of solid lubricant additives' impact on the machining process could be studied. 


\section{Acknowledgments}

This work is supported by Fundamental Research Funds of Shandong University [2019HW040]. Future for Young Scholars of Shandong University, China (31360082064026).

Availability of data and material : The corresponding image data is made available on request.

Code availability: Not applicable

\section{Declarations}

Conflicts of interest: The authors declare no conflict of interest.

Ethics approval: Not applicable

Consent to participate: Not applicable

Consent for publication: Not applicable

\section{CRediT authorship contribution statement}

Vinothkumar Sivalingam: Conceptualization, Experimental work \& Data curation, Writing - review \& editing. Ganeshkumar Poongavanam: MCDM approach, Data curation and Writing - review \& editing, Yuvaraj Natarajan: Technical Validation, Jie Sun: Conceptualization \& Supervision.

\section{References}

1. Marques, A.; Suarez, M.P.; Sales, W.F.; Machado, Á.R. Turning of Inconel 718 with whisker-reinforced ceramic tools applying vegetable-based cutting fluid mixed with solid lubricants by MQL. Journal of Materials Processing Technology 2019, 266, 530-543.

2. Li, L.; He, N.; Wang, M.; Wang, Z. High speed cutting of Inconel 718 with coated carbide and ceramic inserts. Journal of materials processing technology 2002, 129, 127-130.

3. Gaitonde, V.; Karnik, S.; Figueira, L.; Davim, J.P. Machinability investigations in hard turning of AISI D2 cold work tool steel with conventional and wiper ceramic inserts. International Journal of Refractory Metals and Hard Materials 2009, 27, 754-763.

4. Gupta, M.K.; Jamil, M.; Wang, X.; Song, Q.; Liu, Z.; Mia, M.; Hegab, H.; Khan, A.M.; Collado, A.G.; Pruncu, C.I. Performance evaluation of vegetable oil-based nano-cutting fluids in environmentally friendly machining of inconel-800 alloy. Materials 2019, 12, 2792.

5. Singh, G.; Pruncu, C.I.; Gupta, M.K.; Mia, M.; Khan, A.M.; Jamil, M.; Pimenov, D.Y.; Sen, B.; Sharma, V.S. Investigations of machining characteristics in the upgraded MQL-assisted turning of pure titanium alloys using evolutionary algorithms. Materials 2019, 12, 999.

6. Krolczyk, G.; Maruda, R.; Krolczyk, J.; Wojciechowski, S.; Mia, M.; Nieslony, P.; Budzik, G. Ecological trends in machining as a key factor in sustainable production-a review. Journal of Cleaner Production 2019, 218, 601-615. 
7. Zhang, B.; Jessee, N.M.; Yoshiki, S. High-speed turning of Inconel 718 by using TiAlN-and (Al, Ti) N-coated carbide tools. The International Journal of Advanced Manufacturing Technology 2018, 96, 2141-2147.

8. Çelik, A.; Alağaç, M.S.; Turan, S.; Kara, A.; Kara, F. Wear behavior of solid SiAlON milling tools during high speed milling of Inconel 718. Wear 2017, 378, 58-67.

9. Nath, C.; Kapoor, S.G.; DeVor, R.E.; Srivastava, A.K.; Iverson, J. Design and evaluation of an atomization-based cutting fluid spray system in turning of titanium alloy. Journal of Manufacturing Processes 2012, 14, 452-459.

10.Sivalingam, V.; Zan, Z.; Sun, J.; Selvam, B.; Gupta, M.K.; Jamil, M.; Mia, M. Wear behaviour of whisker-reinforced ceramic tools in the turning of Inconel 718 assisted by an atomized spray of solid lubricants. Tribology International 2020, 148, 106235.

11.Sartori, S.; Ghiotti, A.; Bruschi, S. Solid lubricant-assisted minimum quantity lubrication and cooling strategies to improve Ti6Al4V machinability in finishing turning. Tribology International 2018, 118, 287-294.

12.Rajeswari, B.; Amirthagadeswaran, K. Experimental investigation of machinability characteristics and multi-response optimization of end milling in aluminium composites using RSM based grey relational analysis. Measurement 2017, 105, 78-86.

13.Debnath, S.; Reddy, M.M.; Yi, Q.S. Environmental friendly cutting fluids and cooling techniques in machining: a review. Journal of cleaner production 2014, 83, 33-47.

14.Sait, A.N.; Aravindan, S.; Haq, A.N. Optimisation of machining parameters of glass-fibrereinforced plastic (GFRP) pipes by desirability function analysis using Taguchi technique. The international journal of advanced manufacturing technology 2009, 43, 581-589.

15.Singaravel, B.; Selvaraj, T. Application of desirability function analysis and utility concept for selection of optimum cutting parameters in turning operation. Journal of Advanced Manufacturing Systems 2016, 15, 1-11.

16.Świercz, R.; Oniszczuk-Świercz, D.; Chmielewski, T. Multi-response optimization of electrical discharge machining using the desirability function. Micromachines 2019, 10, 72.

17.Sharma, V.K.; Rana, M.; Singh, T.; Singh, A.K.; Chattopadhyay, K. Multi-response optimization of process parameters using Desirability Function Analysis during machining of EN31 steel under different machining environments. Materials Today: Proceedings 2021, 44, 3121-3126.

18.Poongavanam, G.; Sivalingam, V.; Prabakaran, R.; Salman, M.; Kim, S.C. Selection of the best refrigerant for replacing R134a in automobile air conditioning system using different MCDM methods: A comparative study. Case Studies in Thermal Engineering 2021, 27, 101344.

19.Singaravel, B.; Shankar, D.P.; Prasanna, L. Application of MCDM method for the selection of optimum process parameters in turning process. Materials Today: Proceedings 2018, 5, 13464-13471.

20.Ghenai, C.; Albawab, M.; Bettayeb, M. Sustainability indicators for renewable energy systems using multi-criteria decision-making model and extended SWARA/ARAS hybrid method. Renewable Energy 2020, 146, 580-597.

21.Marichamy, M.; Babu, S. The selection of optimum process parameters on A319 aluminum alloy in friction stir welding MCDM method. Materials Today: Proceedings 2021, 37, 228231.

22.Kumar, A.; Rai, R.N. Optimisation of EDM process parameters for AA7050-10 (WT)\% B4C composite through ARAS, grey and Taguchi technique. International Journal of Materials and Product Technology 2019, 59, 102-120.

23.Ramezanali, A.K.; Feizi, F.; Jafarirad, A.; Lotfi, M. Application of Best-Worst method and Additive Ratio Assessment in mineral prospectivity mapping: A case study of vein-type 
copper mineralization in the Kuhsiah-e-Urmak Area, Iran. Ore Geology Reviews 2020, 117, 103268.

24.Goswami, S.S.; Behera, D.K. Implementation of ENTROPY-ARAS decision making methodology in the selection of best engineering materials. Materials Today: Proceedings 2021, 38, 2256-2262.

25.Balki, M.K.; Erdoğan, S.; Aydın, S.; Sayin, C. The optimization of engine operating parameters via SWARA and ARAS hybrid method in a small SI engine using alternative fuels. Journal of Cleaner Production 2020, 258, 120685.

26.Çolak, M.; Kaya, İ. Multi-criteria evaluation of energy storage technologies based on hesitant fuzzy information: a case study for Turkey. Journal of Energy Storage 2020, 28, 101211.

27.Radović, D.; Stević, Ž.; Pamučar, D.; Zavadskas, E.K.; Badi, I.; Antuchevičiene, J.; Turskis, Z. Measuring performance in transportation companies in developing countries: a novel rough ARAS model. Symmetry 2018, 10, 434.

28.Ghorabaee, M.K.; Amiri, M.; Zavadskas, E.K.; Hooshmand, R.; Antuchevičienė, J. Fuzzy extension of the CODAS method for multi-criteria market segment evaluation. Journal of Business Economics and Management 2017, 18, 1-19.

29.Karaşan, A.; Boltürk, E.; Kahraman, C. A novel neutrosophic CODAS method: Selection among wind energy plant locations. Journal of Intelligent \& Fuzzy Systems 2019, 36, 14911504.

30.Badi, I.; Shetwan, A.G.; Abdulshahed, A.M. Supplier selection using COmbinative Distance-based ASsessment (CODAS) method for multi-criteria decision-making. In Proceedings of Proceedings of The 1st International Conference on Management, Engineering and Environment (ICMNEE); pp. 395-407.

31.Ren, J. Sustainability prioritization of energy storage technologies for promoting the development of renewable energy: A novel intuitionistic fuzzy combinative distance-based assessment approach. Renewable Energy 2018, 121, 666-676.

32.Li, H.; Wang, W.; Fan, L.; Li, Q.; Chen, X. A novel hybrid MCDM model for machine tool selection using fuzzy DEMATEL, entropy weighting and later defuzzification VIKOR. Applied Soft Computing 2020, 91, 106207.

33.Ijadi Maghsoodi, A.; Ijadi Maghsoodi, A.; Poursoltan, P.; Antucheviciene, J.; Turskis, Z. Dam construction material selection by implementing the integrated SWARA - CODAS approach with target-based attributes. Archives of Civil and Mechanical Engineering 2019, 19, 1194-1210.

34.Roy, J.; Das, S.; Kar, S.; Pamučar, D. An extension of the CODAS approach using intervalvalued intuitionistic fuzzy set for sustainable material selection in construction projects with incomplete weight information. Symmetry 2019, 11, 393.

35.Karagoz, S.; Deveci, M.; Simic, V.; Aydin, N.; Bolukbas, U. A novel intuitionistic fuzzy MCDM-based CODAS approach for locating an authorized dismantling center: a case study of Istanbul. Waste Management \& Research 2020, 38, 660-672.

36.Harrington, E.C. The desirability function. Industrial quality control 1965, 21, 494-498.

37.Costa, N.R.; Lourenço, J.; Pereira, Z.L. Desirability function approach: a review and performance evaluation in adverse conditions. Chemometrics and Intelligent Laboratory Systems 2011, 107, 234-244.

38.Yazdani, M.; Torkayesh, A.E.; Santibanez-Gonzalez, E.D.; Otaghsara, S.K. Evaluation of renewable energy resources using integrated Shannon Entropy-EDAS model. Sustainable Operations and Computers 2020, 1, 35-42.

39.Zavadskas, E.K.; Turskis, Z. A new additive ratio assessment (ARAS) method in multicriteria decision-making. Technological and economic development of economy 2010, $16,159-172$. 
40.Özbek, A.; Erol, E. Ranking of factoring companies in accordance with ARAS and COPRAS methods. International Journal of Academic Research in Accounting, Finance and Management Sciences 2017, 7, 105-116.

41.Ferreira, R.; Carou, D.; Lauro, C.; Davim, J. Surface roughness investigation in the hard turning of steel using ceramic tools. Materials and Manufacturing Processes 2016, 31, 648652.

42.Sivalingam, V.; Zhuoliang, Z.; Jie, S.; Baskaran, S.; Yuvaraj, N.; Gupta, M.K.; Aqib, M.K. Use of atomized spray cutting fluid technique for the turning of a nickel base superalloy. Materials and Manufacturing Processes 2021, 36, 373-380.

43. Chavan, V.; Kadam, S.; Sadaiah, M. Performance of alumina-based ceramic inserts in highspeed machining of nimonic 80A. Materials and Manufacturing Processes 2019, 34, 8-17.

44.Gupta, S.; Venkatesan, K.; Devendiran, S.; Mathew, A.T. Experimental investigation of IN725 under different cooling environments using new tool holder. Materials and Manufacturing Processes 2019, 34, 637-647.

45.Klocke, F.; Nobel, C.; Veselovac, D. Influence of tool coating, tool material, and cutting speed on the machinability of low-leaded brass alloys in turning. Materials and Manufacturing Processes 2016, 31, 1895-1903.

46.Zhuang, K.; Zhu, D.; Zhang, X.; Ding, H. Notch wear prediction model in turning of Inconel 718 with ceramic tools considering the influence of work hardened layer. Wear 2014, 313, 63-74. 


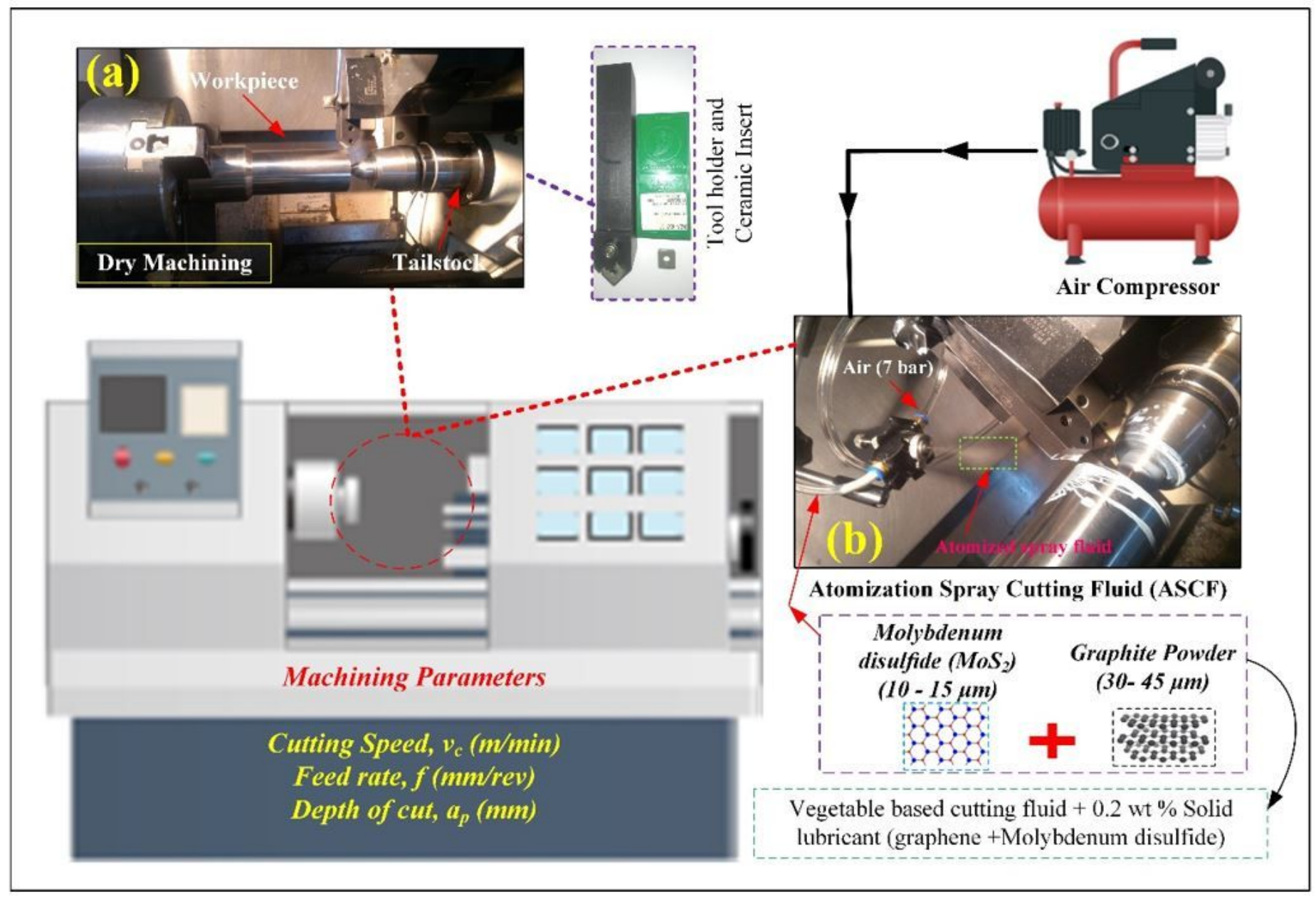

Figure 1

Schematic experiment setup of (a) Dry (b) ASCF machining. 


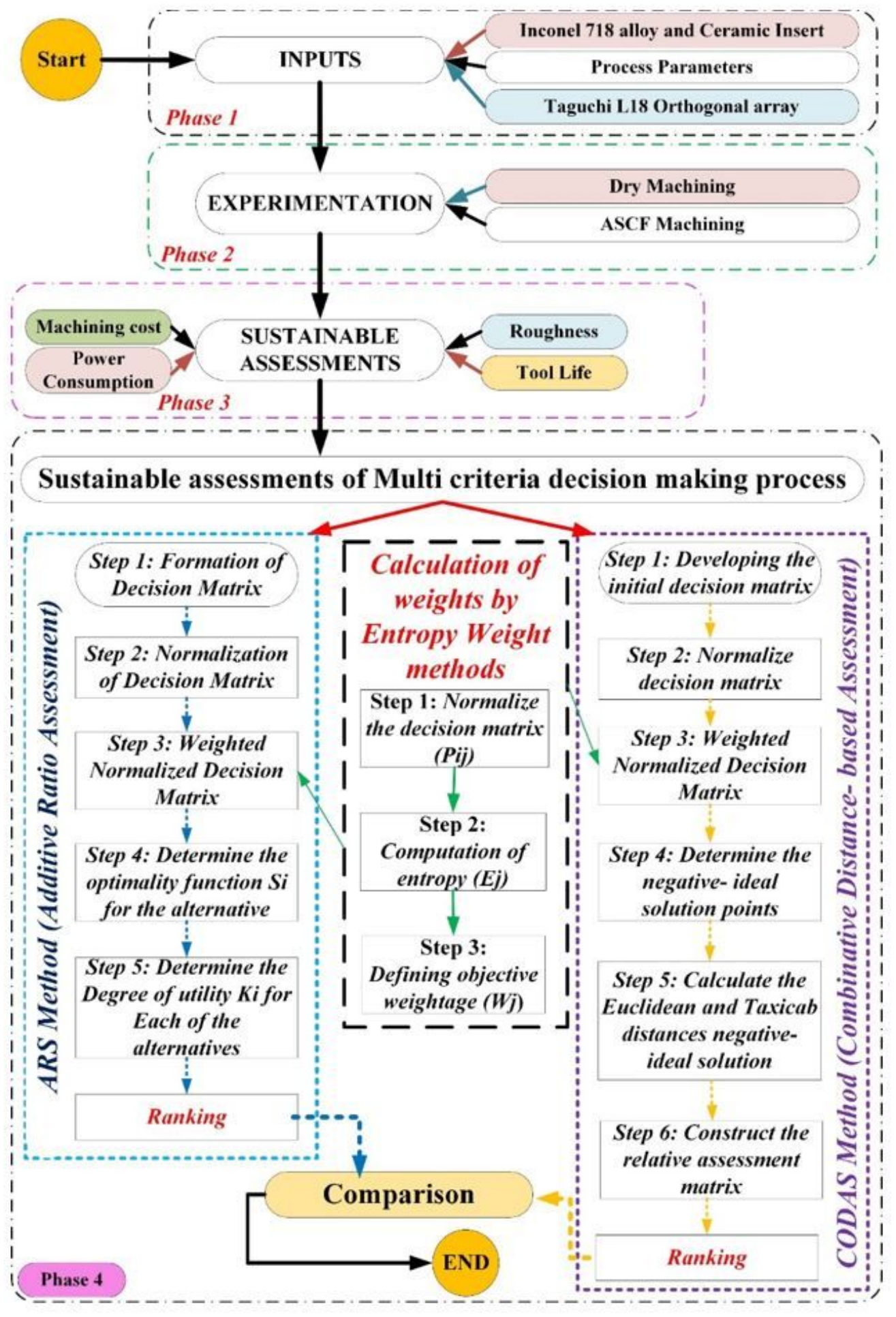

Figure 2

Schematic flow chart of MCDM methods 


\section{Main Effects Plot for Composite Desirability}

\section{Data Means}

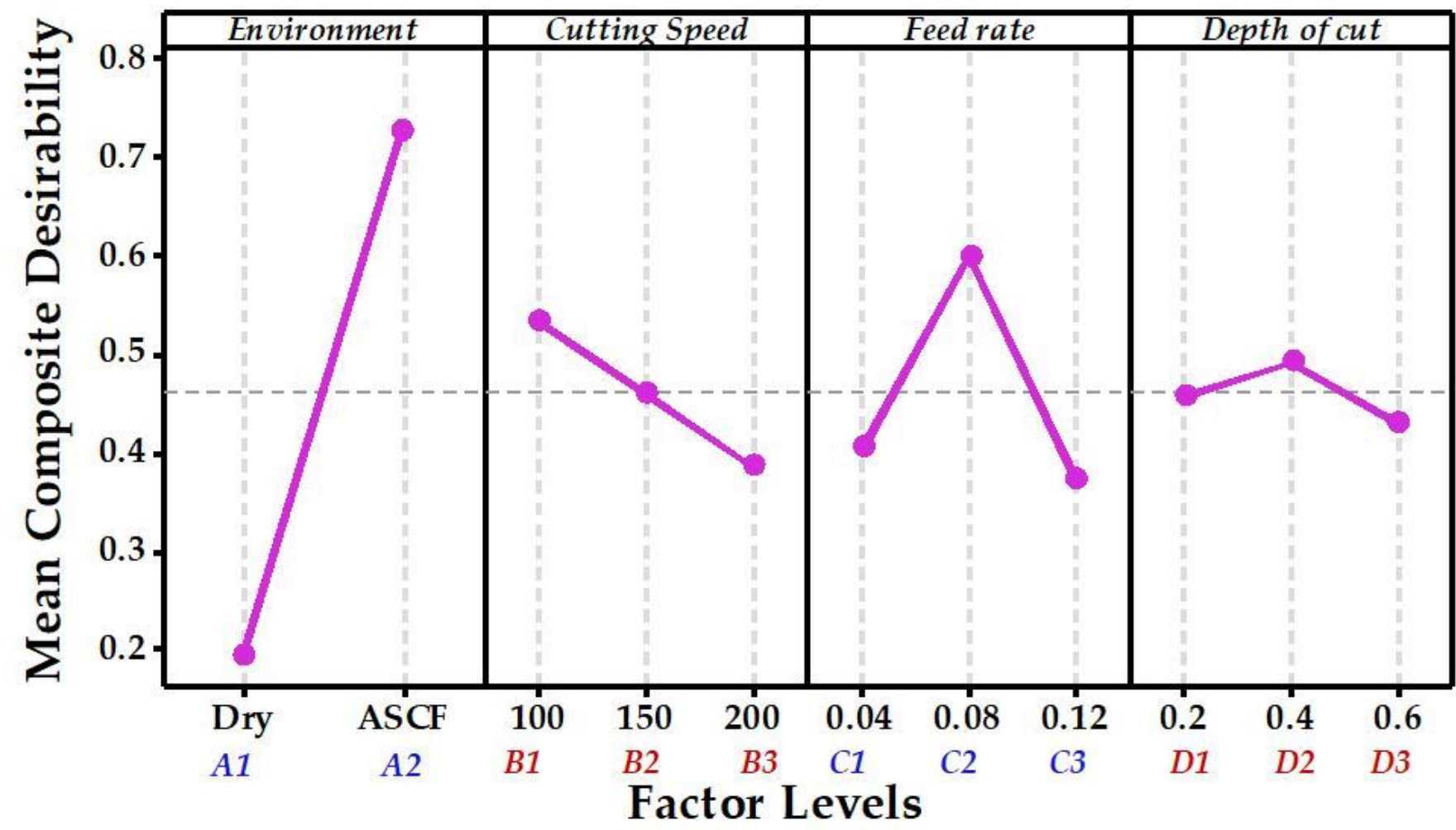

Figure 3

Mean composite desirability. 


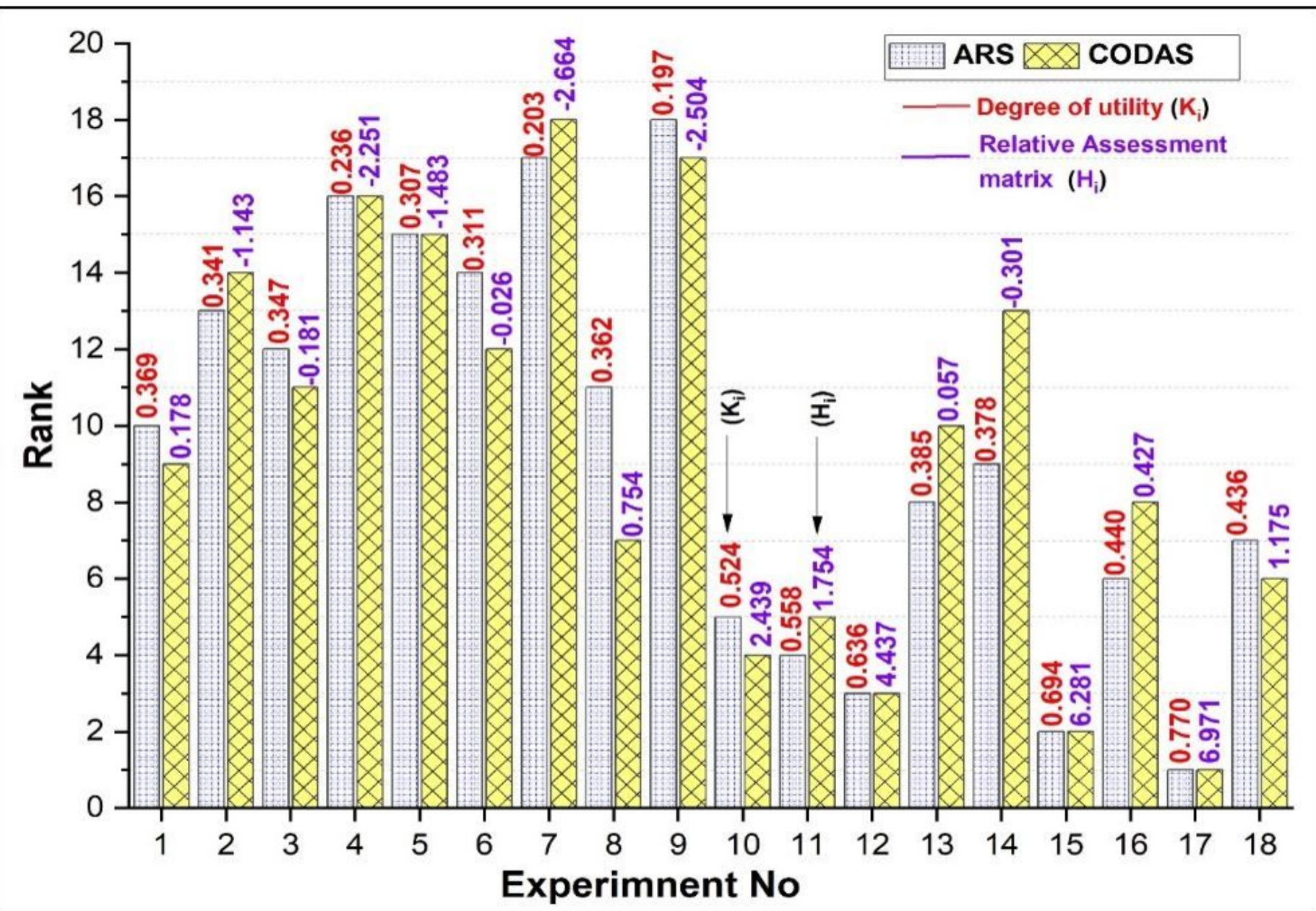

Figure 4

Rank values of a different experiment. 


\section{OPTICAL LIGHT MICROSCOPE}
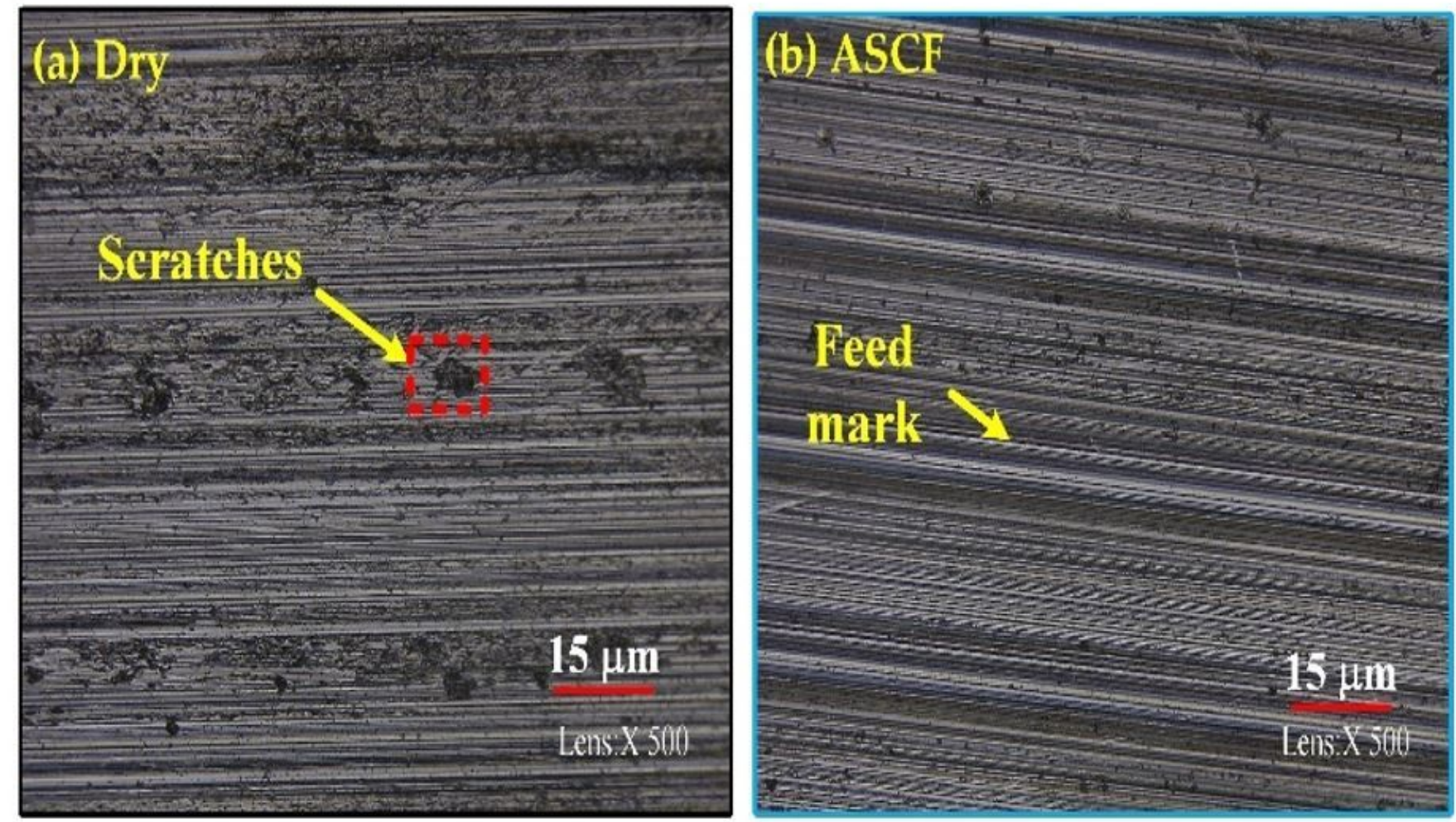

$$
v_{\mathrm{c}}=200 \mathrm{~m} / \mathrm{min}, f=0.08 \mathrm{~mm} / \mathrm{rev} \text { and } \mathrm{a}_{\mathrm{p}}=0.2 \mathrm{~mm}
$$

Figure 5

Machined surface defects (a) Dry (b) ASCF machining 


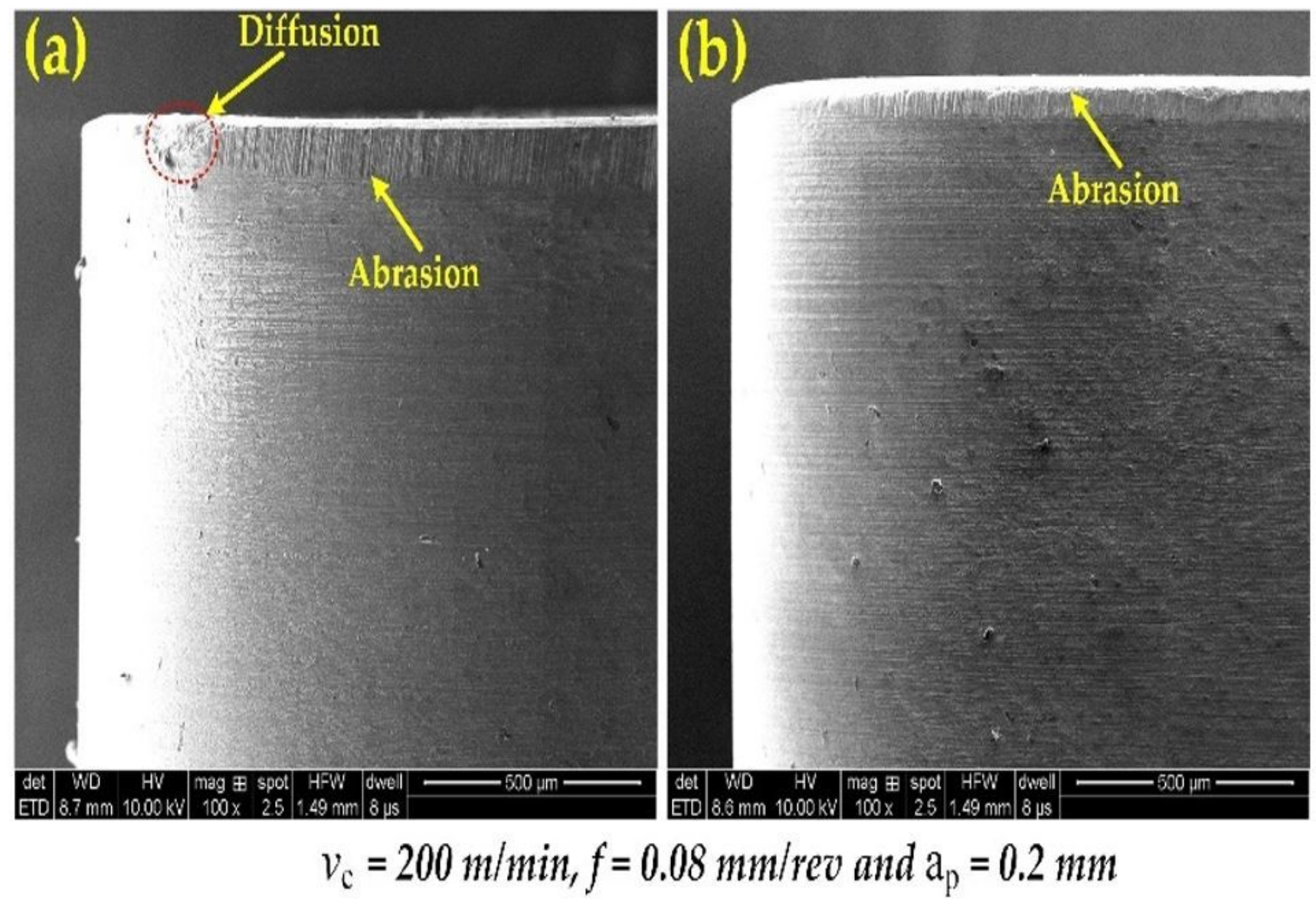

Figure 6

SEM images (a) Dry (b) ASCF machining 